\title{
Claude Duchet - Dominique Pety. Philippe Régnier, Bibliographie du dix-neuvième siècle. Année 2002
}

\section{Emanuele Kanceff}

\section{(2) OpenEdition}

1 Journals

\section{Edizione digitale}

URL: http://journals.openedition.org/studifrancesi/33546

DOI: 10.4000/studifrancesi.33546

ISSN: 2421-5856

\section{Editore}

Rosenberg \& Sellier

\section{Edizione cartacea}

Data di pubblicazione: 1 décembre 2005

Paginazione: 671

ISSN: 0039-2944

\section{Notizia bibliografica digitale}

Emanuele Kanceff, «Claude Duchet - Dominique Pety. Philippe Régnier, Bibliographie du dix-neuvième siècle. Année 2002», Studi Francesi [Online], 147 (XLX | III) | 2005, online dal 30 novembre 2015, consultato il 18 avril 2021. URL: http://journals.openedition.org/studifrancesi/33546 ; DOI: https:// doi.org/10.4000/studifrancesi.33546

\section{Questo documento è stato generato automaticamente il 18 avril 2021.}

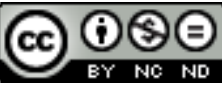

Studi Francesi è distribuita con Licenza Creative Commons Attribuzione - Non commerciale - Non opere derivate 4.0 Internazionale. 
Claude Duchet - Dominique Pety. Philippe Régnier, Bibliographie du dix-neuvième siècle. Année 2002

Emanuele Kanceff 


\section{NOTIZIA}

CLAUDE DUCHET - DOMINIQUE PETY. PHILIPPE RÉGNIER, Bibliographie du dix-neuvième siècle. Année 2002, Paris, Société des études romantiques et dix-neuvièmistes, Presses Sorbonne Nouvelle, 2004, pp. 265.

Segnaliamo questa bibliografia generale di Lettere, Arti, Scienze e Storia, che, iniziata nel 1998, è giunta ora al suo quinto volume. La formula è certamente originale: non la produzione annuale di una sola disciplina, in una sola nazione e in una sola lingua, ma un secolo, uno solo, ma tutto intero, dal 1800 al 1914, in letteratura, scienze umane, scienze esatte, nella storia, nelle arti, insomma in una visione di storia della civiltà, in Francia certamente ma ugualmente in Europa e in ogni parte del mondo. Inoltre, altra originalità della bibliografia, la mancanza di formule prefissate, il rifiuto di imprigionare il tempo in formule e in generi, l'osservazione senza pregiudizi. $\mathrm{Ne}$ consegue un ordinamento secondo i tipi di lavori: edizioni di testi; Opere non collettive; Opere collettive; Riviste e pubblicazioni periodiche. Va da sé che in un'opera così vasta gli indici sono fondamentali. Qui abbiamo un indice dei nomi, che raccoglie tutti i nomi di persona relativi al secolo; un indice critico, che raccoglie i nomi di tutti coloro che nell'anno 2002 hanno contribuito, a qualunque titolo (autore, collaboratore, traduttore, editore scientifico, presentatore, illustratore), a diffondere la conoscenza del secolo con le loro pubblicazioni; un indice tematico, che riguarda tutte le sezioni e comprende le parole chiave di tutte le materie e attività considerate, così come le referenze e i nomi propri che non appartengono all'Ottocento. 